\title{
Production of extracellular matrix by Candida albicans biofilms
}

\author{
S. P. HAWSER*, G. S. BAILLIE and L. JULIA DOUGLAS
}

Division of Infection and Immunity, Institute of Biomedical and Life Sciences, University of Glasgow, Glasgow G12 800

\begin{abstract}
Growth of Candida albicans biofilms and production of extracellular matrix were monitored by dry weight, colorimetric and radioisotope assays, and by scanning electron microscopy. Under static incubation conditions synthesis of matrix material was minimal, but increased dramatically when developing biofilms were subjected to a liquid flow with the result that the cells were enveloped in extracellular polymer. These findings suggest that production of matrix material could contribute to the resistance of biofilm cells to antifungal agents in vivo.
\end{abstract}

\section{Introduction}

The major complication associated with the use of medical implants such as intravascular catheters or joint prostheses is infection. Micro-organisms can colonise these devices and form biofilms consisting of layers of cells embedded within a matrix material $[1-7]$. Implant infections are usually difficult to treat because biofilm micro-organisms are resistant to antimicrobial therapy $[2,7,8]$. Although fungal implant infections are less common than bacterial ones, they tend to be more serious $[4,9]$. They are most often caused by the pathogenic Candida spp, particularly $C$. albicans, which is now recognised as one of the most important agents of hospital-acquired infection [10].

Recently, a model system was devised for studying candida biofilms growing on the surface of small disks of catheter material $[11,12]$. Growth of the biofilms was monitored quantitatively by dry weight measurements and by colorimetric or radioisotope assays. Biofilm formation by 15 different isolates of $C$. albicans and a number of other Candida spp. was investigated with this system. Previous studies included examination of biofilm formation by scanning electron microscopy (SEM). This demonstrated that yeast-phase cells of $C$. albicans adhered to the surface of polyvinyl chloride (PVC) catheter disks and, during subsequent incubation for $48 \mathrm{~h}$, formed a dense biofilm consisting

Received 9 June 1997; accepted 11 July 1997.

Corresponding author: Dr L. J. Douglas.

*Present address: Hoechst Marion Roussel, 102 Route de Noisy, 93235 Romainville Cedex, France. of yeast cells, germ tubes, pseudohyphae and hyphae. Extracellular polymeric material was visible on the surface of some of these morphological forms, but its production under the static incubation conditions used was not extensive [11]. This paper reports that synthesis of the matrix material by growing biofilms can be dramatically increased by incubating the catheter disks with gentle shaking.

\section{Materials and methods}

\section{Organism and culture conditions}

C. albicans GDH 2346 was grown in Yeast Nitrogen Base Medium (Difco) containing glucose or galactose as described previously $[11,13]$. Before use in biofilm experiments, all washed cell suspensions were adjusted to an $\mathrm{OD}_{520}$ of 0.8 .

\section{Biofilm formation}

Biofilms were grown on small disks (surface area, $0.5 \mathrm{~cm}^{2}$ ) cut from PVC central venous catheters as described previously [11]. Briefly, the disks were placed in wells of 24-well Nunclon tissue culture plates and standardised cell suspension $(80 \mu \mathrm{l})$ was applied to the surface of each one. After incubation for $1 \mathrm{~h}$ at $37^{\circ} \mathrm{C}$ (adhesion period), non-adherent organisms were removed by washing with $0.15 \mathrm{M}$ phosphatebuffered saline ( $\mathrm{pH}$ 7.2). The disks were then incubated in the wells for $48 \mathrm{~h}$ at $37^{\circ} \mathrm{C}$, submerged in $1 \mathrm{ml}$ of growth medium (biofilm formation). In other experiments, biofilms were formed on catheter disks incubated with shaking $(2-60 \mathrm{rpm})$, instead of statically. After the 1-h adhesion period (static incubation), nonadherent organisms were removed by washing as 
before. Each disk was then transferred to an Erlenmeyer flask $(100 \mathrm{ml})$ containing $20 \mathrm{ml}$ of growth medium and shaken at the appropriate speed for $48 \mathrm{~h}$ at $37^{\circ} \mathrm{C}$. In control experiments, disks without cells were incubated with or without shaking.

\section{Measurement of biofilm growth}

Quantitative measurements of biofilm growth were made by dry weight determinations and assays involving the incorporation of $\left[{ }^{3} \mathrm{H}\right]$ leucine or reduction of the tetrazolium salt, MTT, as described previously [11].

\section{Scanning electron microscopy (SEM)}

Initially, biofilms were fixed and prepared for SEM by a procedure which involved critical point drying, as described previously [11]. To improve the visualisation of extracellular matrix material, an alternative freezedrying technique [14] was developed. Here, biofilms formed on catheter disks were fixed with glutaraldehyde $2.5 \% \mathrm{v} / \mathrm{v}$ in $0.1 \mathrm{M}$ cacodylate buffer $(\mathrm{pH} 7.0)$, washed three times in distilled water, and then plunged into a liquid propane:isopentane mixture $(2: 1, \mathrm{v}: \mathrm{v})$ at $-196^{\circ} \mathrm{C}$ before freeze-drying under vacuum $\left(10^{-6}\right.$ Torr).
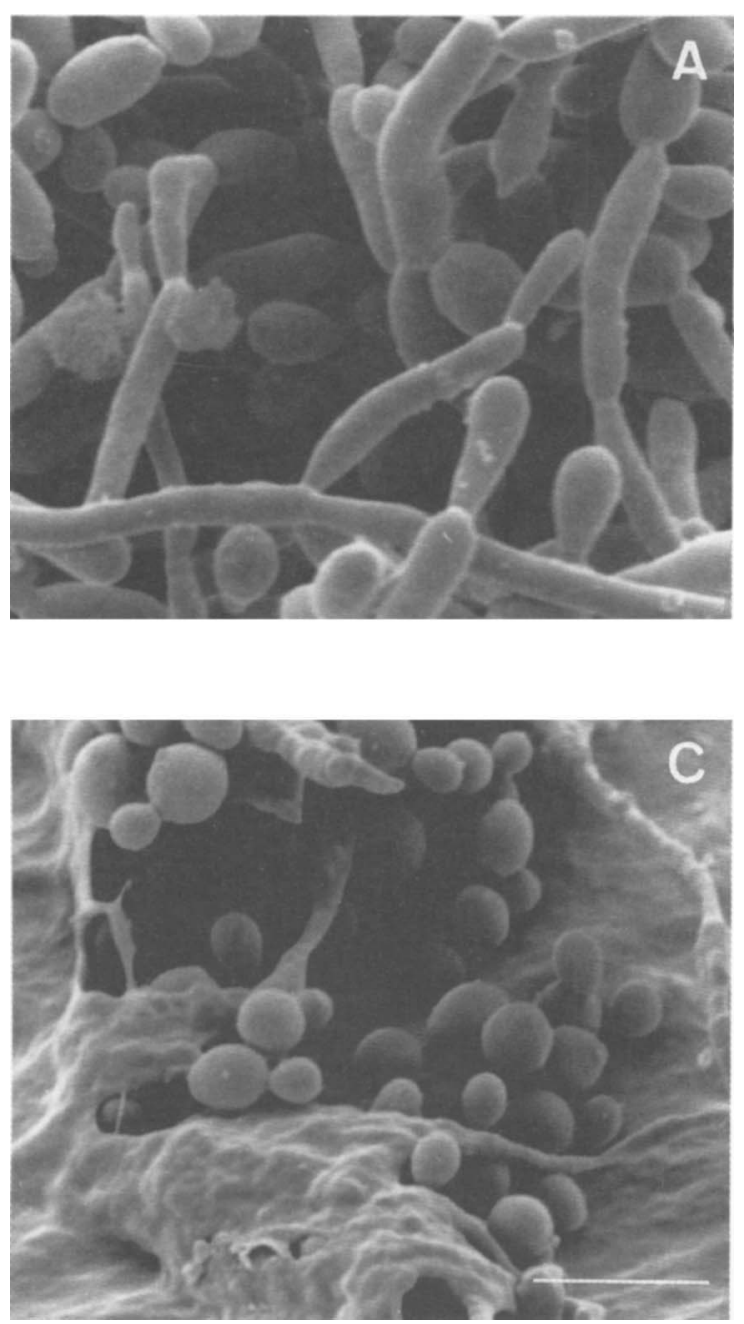

\section{Results and discussion}

Scanning electron microscopy of biofilms formed by $C$. albicans GDH 2346 incubated statically confirmed previous observations [11]: after $48 \mathrm{~h}$ there was a dense network of yeasts, germ tubes, pseudohyphae and hyphae, with small amounts of extracellular polymeric material present on the surface of some of these cells (Fig. 1A). By contrast, incubation of catheter disks with gentle shaking markedly increased the synthesis of extracellular matrix material. Slow shaker speeds (2$5 \mathrm{rpm}$ ) produced biofilms consisting of a mixture of yeasts and hyphae, as before, but the cells were surrounded by a thick extracellular matrix. At higher speeds $(10-30 \mathrm{rpm})$, biofilm cells were largely hidden under an extensive 'canopy' of matrix material (Fig. $1 \mathrm{~B}, \mathrm{C})$. Shaking speeds in excess of $60 \mathrm{rpm}$ virtually precluded biofilm development and very few cells were observed on the catheter surface.

Production of matrix material appeared to be unaffected by the nature and concentration of the carbon source used in the growth medium; media containing $4 \mathrm{mM}$ glucose, $50 \mathrm{mM}$ glucose or $500 \mathrm{mM}$ galactose all gave biofilms with similar amounts of extracellular matrix as judged by SEM. However, investigation of various

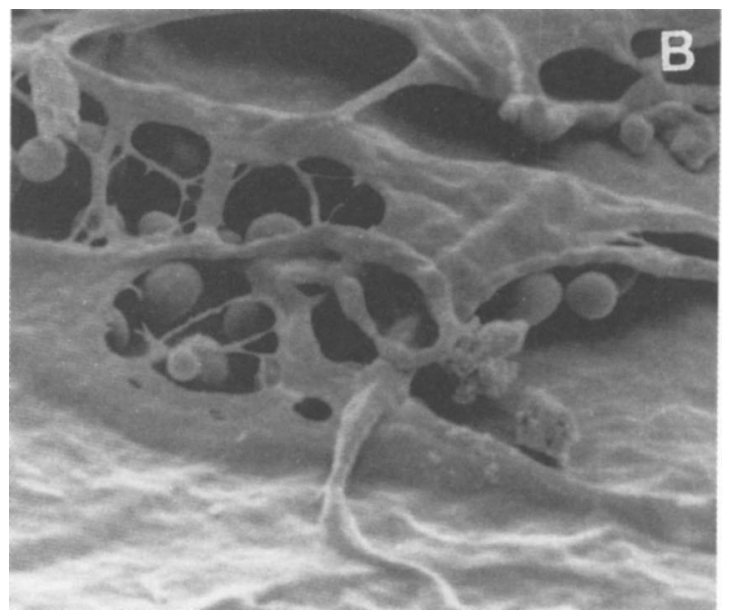

Fig. 1. Scanning electron micrographs of biofilm formation by $C$. albicans GDH 2346 on PVC catheter disks after critical point drying of samples. Biofilms were incubated for $48 \mathrm{~h}$ statically $(\mathrm{A})$, or with shaking at $10-$ $30 \mathrm{rpm}(\mathbf{B}, \mathbf{C})$. Bar, $10 \mu \mathrm{m}$. 

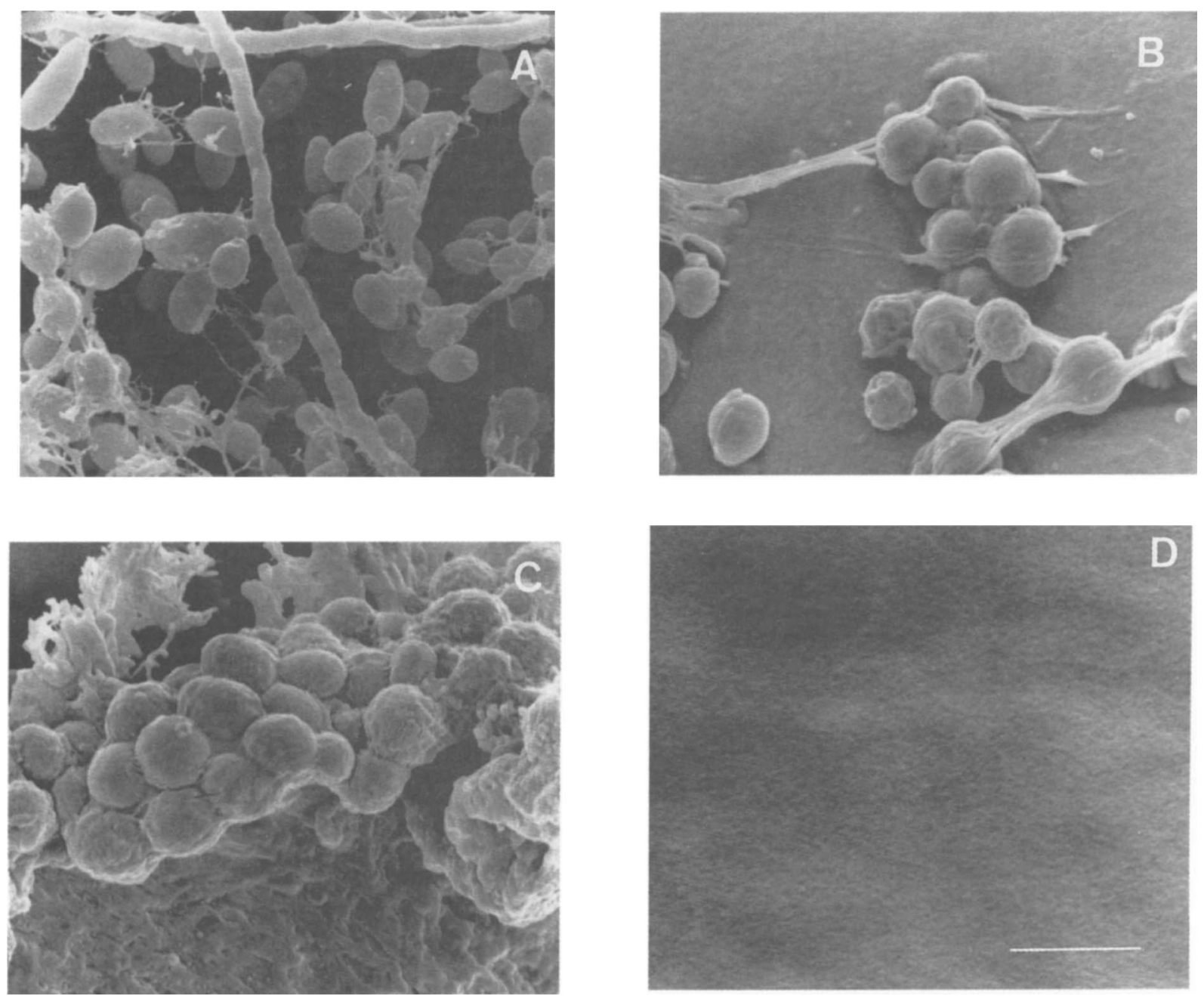

Fig. 2. Scanning electron micrographs of biofilm formation by C. albicans GDH 2346 on PVC catheter disks after freeze-drying of samples. Biofilms were incubated for $48 \mathrm{~h}$ statically (A), or with shaking at $5 \mathrm{rpm}(\mathbf{B})$ or $15 \mathrm{rpm}(\mathbf{C})$. Control disks were shaken at $5 \mathrm{rpm}$ without cells (D). Bar, $10 \mu \mathrm{m}$.

preparative techniques for SEM revealed that the dehydration procedure used markedly affected the extent to which this biofilm structure was preserved. Consistently better results were obtained by a freezedrying technique [14]. With this procedure even biofilms grown statically were seen to contain cells clearly linked together by strands of extracellular polymer (Fig. 2A). Incubation of the catheter disks with slow shaking $(5 \mathrm{rpm})$ increased the synthesis of this material, which seemed to envelope the cells completely (Fig. 2B). At higher speeds, the matrix was very extensive and completely obscured the cells (Fig. 2C). In control experiments where the catheter disks were incubated with shaking in the absence of $C$. albicans, the PVC surface was clearly visible and devoid of extracellular polymer (Fig. 2D). Other dehydration procedures, including air drying or chemical drying with Peldri II [15] and hexamethyldisilizane [16], resulted in little or no preservation of the matrix structure.

Quantitative measurement of biofilms incubated at low shaking speeds $(2-5 \mathrm{rpm})$ gave values similar to those obtained with biofilms which had been incubated statically by all methods used (Table 1). However, at

Table 1. Quantitative measurement of 48-h biofilms of C. albicans GDH 2346 incubated statically or with shaking*

\begin{tabular}{|c|c|c|c|}
\hline $\begin{array}{l}\text { Shaking speed } \\
\text { (rpm) }\end{array}$ & $\begin{array}{l}\text { Dry weight } \\
\text { (mg) }\end{array}$ & $\begin{array}{l}{\left[{ }^{3} \mathrm{H}\right] \text { leucine }} \\
\text { incorporation } \\
\quad(\mathrm{cpm})\end{array}$ & $\begin{array}{l}\text { MTT formazan } \\
\text { formation }\left(A_{540}\right)\end{array}$ \\
\hline 0 & 1.92 & 9765 & 1.16 \\
\hline 2 & 1.94 & 9788 & 1.14 \\
\hline 5 & 1.97 & 9887 & 1.15 \\
\hline 10 & $2.23^{\dagger}$ & $10105^{\dagger}$ & 1.08 \\
\hline 20 & $2.46^{\dagger}$ & $10260^{\dagger}$ & 1.03 \\
\hline 30 & $2.44^{\dagger}$ & $10260^{\dagger}$ & 1.03 \\
\hline 45 & $1.41^{\ddagger}$ & $7075^{\ddagger}$ & $0.78^{+}$ \\
\hline 60 & ND & ND & ND \\
\hline
\end{tabular}

ND, not detected.

${ }^{*}$ Each value is the mean of three independent experiments done in triplicate.

†Value significantly different at $\mathrm{p}<0.05$ from that obtained with strain GDH 2346 grown under static conditions.

${ }^{*}$ Value significantly different at $p<0.001$ from that obtained with strain GDH 2346 grown under static conditions. 
higher speeds $(10-30 \mathrm{rpm})$, values for dry weights and $\left[{ }^{3} \mathrm{H}\right]$ leucine incorporation were significantly greater $(p<0.05)$. Interestingly, there were no corresponding increases in MTT formazan formation (Table 1). These differences may reflect the differing sensitivities of the three types of assay to the presence of extracellular matrix material. When biofilms were incubated at a shaking speed of $45 \mathrm{rpm}$, there were significant decreases $(p<0.001)$ in all three parameters as compared with values obtained in the static system. At the highest shaking speed of $60 \mathrm{rpm}$, quantitative measurements confirmed the SEM observations that biofilm formation was completely inhibited, presumably due to the intense shear forces generated at this speed (Table 1).

The matrix material of bacterial biofilms, sometimes known as the glycocalyx, appears to consist largely of exopolysaccharides. It is thought to act as a physical barrier to the penetration of certain antibiotics and may partly account for the recalcitrance of biofilms to therapeutic agents [8]. Some bacteria are known to produce copious amounts of slimy matrix; this has been well documented with coagulase-negative staphylococci, which are the commonest bacterial agents of implant infection [17]. Extensive production of matrix material or 'slime' by fungal biofilms has not been reported previously. The present results indicate that gentle shaking to produce a flow of liquid over developing Candida biofilms increases the synthesis of extracellular material. Such conditions may resemble those found in vivo and biofilms in vivo may therefore afford greater protection from both antifungal agents and host defence mechanisms. Preliminary results indicate that candida biofilms grown with shaking are even more resistant to amphotericin B than biofilms grown statically, at least over short time periods (unpublished observations). The chemical nature of the extracellular matrix material and the mechnisms by which it is produced are unknown, although it seems likely that it will contain mannoproteins, cell wall components including adhesins that can be sloughed off the yeast surface in planktonic cultures [18].

This work was supported by grants (92/3A and 94/22A) from the Sir
Jules Thorn Charitable Trust. We are indebted to L. Tetley and M. Mullin for assistance with the SEM studies.

\section{References}

1. Bisno AL, Waldvogel FA. Infections associated with indwelling medical devices. Washington, DC, American Society for Microbiology. 1989.

2. Costerton JW, Cheng KJ, Geesey GG et al. Bacterial biofilms in nature and disease. Annu Rev Microbiol 1987; 41: 435-464.

3. Costerton JW, Lewandowski Z, Caldwell DE, Korber DR, Lappin-Scott HM. Microbial biofilms. Annu Rev Microbiol 1995; 49: 711-745.

4. Dougherty SH. Pathobiology of infection in prosthetic device. Rev Infect Dis 1988; 10: 1102-1117.

5. Elliott TSJ. Intravascular-device infections. $J$ Med Microbiol 1988; 27: 161-167.

6. Goldman DA, Pier GB. Pathogenesis of infections related to intravascular catheterization. Clin Microbiol Rev 1993; 6: $176-192$.

7. Gristina AG. Biomaterial-centered infection: microbial adhesion versus tissue integration. Science 1987; 237: 1588-1595.

8. Brown MRW, Gilbert P. Sensitivity of biofilms to antimicrobial agents. J Appl Bacteriol Symp Suppl 1993; 74: 87S-97S.

9. Cox GM, Perfect JR. Fungal infections. Curr Opin Infect Dis 1993; 6: 422-426.

10. Pittet D, Wenzel RP. Nosocomial bloodstream infections: secular trends in rates, mortality, and contribution to total hospital deaths. Arch Intern Med 1995; 155: 1177-1184.

11. Hawser SP, Douglas LJ. Biofilm formation by Candida species on the surface of catheter materials in vitro. Infect Immun 1994; 62: 915-921.

12. Hawser SP, Douglas LJ. Resistance of Candida albicans biofilms to antifungal agents in vitro. Antimicrob Agents Chemother 1995; 39: 2128-2131.

13. McCourtie J, Douglas LJ. Relationship between cell surface composition of Candida albicans and adherence to acrylic after growth on different carbon sources. Infect Immun 1981; 32: 1234-1241.

14. Steinbrecht RA, Müller $M$. Freeze-substitution and freezedrying. In: Steinbrecht RA, Zierold K (eds) Cryotechniques in biological electron microscopy. Berlin, Springer-Verlag. 1987: $149-172$.

15. Kennedy JR, Williams RW, Gray JP. Use of Peldri II (a fluorocarbon solid at room temperature) as an alternative to critical point drying for biological tissues. $J$ Electron Microsc Tech 1989; 11: 117-125.

16. Nation JL. A new method using hexamethyldisilazane for preparation of soft insect tissues for scanning electron microscopy. Stain Technol 1983; 58: 347-351.

17. Hussain M, Wilcox MH, White PJ. The slime of coagulasenegative staphylococci: biochemistry and relation to adherence. FEMS Microbiol Rev 1993; 104: 191-208.

18. McCourtie J, Douglas LJ. Extracellular polymer of Candida albicans: isolation, analysis and role in adhesion. $J$ Gen Microbiol 1985; 131: 495-503. 